\title{
Enhancement of Efficacy of Bupivacaine by Adding Dexamethasone in Paediatric Caudal Epidural for Orchidopexy
}

\author{
Deepti N. Anandani'1, Sonal A. Shah², Rahil H. Belim³, Ajay G. Prajapati ${ }^{4}$ \\ ${ }^{1}$ Assistant Professor, Department of Anaesthesiology, NHL Medical College, Ahmedabad, Gujarat, India. \\ ${ }^{2}$ Assistant Professor, Department of Anaesthesiology, NHL Medical College, Ahmedabad, Gujarat, India. \\ $33^{\text {rd }}$ Year Resident, Department of Anaesthesiology, NHL Medical College, Ahmedabad, Gujarat, India. \\ ${ }^{4} 3^{\text {rd }}$ Year Resident, Department of Anaesthesiology, NHL Medical College, Ahmedabad, Gujarat, India.
}

\section{ABSTRACT}

\section{BACKGROUND}

Administration of Dexamethasone might reduce post-operative pain in adults. We evaluated whether a caudal block of $0.1 \mathrm{mg} / \mathrm{Kg}$ dexamethasone adjuvant with bupivacaine improves analgesic efficacy in children undergoing orchidopexy. Dexamethasone is highly selective long acting, very potent corticosteroids. It is 10 times more potent than hydrocortisone. Caudal block is the anaesthesia of choice for lower abdominal surgeries in paediatric patients. The effect of single bolus caudal block can be prolonged by adding adjuvant. We studied the effects of dexamethasone as adjuvant to bupivacaine in caudal block in paediatric orchidopexy.

\section{METHODS}

The primary outcome measure was the time to first analgesic requirement and the number of analgesic doses required in the first 24 hours after surgery. Intraoperative and post-operative hemodynamic variables were comparable in the two groups. Post-operative nausea and vomiting (PONV) and other adverse effects were recorded. 60 patients of age 1-6 years scheduled for paediatric orchidopexy under caudal epidural block were randomly divided into two equal groups. In Group B $(\mathrm{n}=30)$ caudal block was given with bupivacaine $0.25 \% 1 \mathrm{ml} / \mathrm{Kg}$ and in Group-BD $(\mathrm{n}=30)$ Bupivacaine $0.25 \% 1 \mathrm{ml} / \mathrm{Kg}+0.1 \mathrm{mg} / \mathrm{Kg}$ dexamethasone was used. Duration of analgesia and analgesic requirement in 24 hours and side effects were recorded.

\section{RESULTS}

Duration of post-operative analgesia in Group BD $10.6+2.61$ hour and in Group B $3.5+0.67$ hours requirement of post-operative analgesia was more in Group B than Group BD.

\section{CONCLUSIONS}

The addition of dexamethasone $0.1 \mathrm{mg} / \mathrm{Kg}$ to bupivacaine for caudal block can significantly improve analgesic efficacy in children undergoing paediatric orchidopexy.

\section{KEY WORDS}

Postoperative, Caudal Block, Analgesia, Dexamethasone, Inguinal Hernia Repair Surgery, Bupivacaine
Corresponding Author:

Dr. Sonal A. Shah,

Vardhman, Near Jain Temple,

Usmanpura, Ashram Road,

Ahmedabad-380014,

Gujarat, India.

E-mail:drsonal.shah@yahoo.com

DOI: $10.14260 / j e m d s / 2019 / 562$

Financial or Other Competing Interests: None.

How to Cite This Article:

Anandani DN, Shah SA, Belim RH, et al. Enhancement of efficacy of bupivacaine by adding dexamethasone in paediatric caudal epidural for orchidopexy. J. Evolution Med. Dent. Sci. 2019;8(32):2582-2586, DOI: $10.14260 / j e m d s / 2019 / 562$

Submission 11-06-2019, Peer Review 25-07-2019, Acceptance 01-08-2019, Published 12-08-2019. 


\section{BACKGROUND}

Paediatric orchidopexy is a commonly performed surgery from 3 months onwards and is associated with post-operative pain lasting for several day. ${ }^{(1,2)}$ Children undergoing surgery suffer moderate to severe pain at first post-operative day requiring analgesic for an additional 3 days after surgery. ${ }^{(1,2)}$ Untreated pain may have long-term negative effects on pain sensitivity, immune functioning neurophysiology.(3) In 1970 and 1980 pain in the children to a large extent ignored or under treated compared to adult. Therefore, appropriate management of post-operative pain in children is very important.(4)

Caudal block is one of the most commonly used regional analgesic techniques in paediatrics. (5) It is technically simple, safe and high success rate. To maximize the efficacy of caudal analgesia with local anaesthetic various adjuncts have been investigated such as opioids, $\alpha 2$-agonist, ketamine, neostigmine. (6-7) I have been proved to prolong the duration of analgesia but they are associated with side effect like nausea, hypotension bradycardia, depression, purities and urinary retention. ${ }^{(8-9)}$ Dexamethasone is commonly used perioperatively to manage post-operative pain and vomiting. Dexamethasone have analgesic properties which increase the duration of Block. (10)

The objective of our study is to evaluate the effect of dexamethasone in caudal block for hernia repair surgeries in paediatric patients in terms of prolongation of duration of analgesia requirement of rescue analgesia and any side effects.

\section{METHODS}

This prospective, randomized, controlled study was carried out in V. S. General Hospital during the period of February 2018 to December 2018. Sample size was calculated on the basis of previous studies.(11,12) Sixty patients of age group 1 year to 6 years belonging to ASA grade I and II scheduled for inguinal hernia repair surgeries were included in the study. Written informed consent was obtained from all parents of the children. Patients were excluded if they had

- Known or suspected coagulopathy.

- Hypersensitivity to any of the drugs.

- Abnormality of the sacrum.

- Mental retardation.

- Pre-existing neurological disease.

- Infection at Puncture Site.

All patients included were randomly divided into two groups, Randomization was done by using computer generated random numbers contained in opaque sealed envelopes- Group B: Bupivacaine $0.25 \% 1 \mathrm{ml} / \mathrm{kg}$

Group BD: Bupivacaine 0.25\% $1 \mathrm{ml} / \mathrm{Kg}+$ Dexamethasone $0.1 \mathrm{mg} / \mathrm{kg}$.

\section{Anaesthesia Technique}

All patients were fasted according to the ASA guidelines (2 hours for clear fluid; 4 hours for breast milk; 6 hours for formula milk or light meal). (Patient pre-medicated with Inj. Glycopyrrolate $0.01 \mathrm{mg} / \mathrm{kg}$. Patient were taken to the 0.T. and give inj. ketamine $2 \mathrm{mg} / \mathrm{Kg}$ and attached all the monitors ECG, SpO2, NIBP. Caudal Epidural block was given. Anaesthesia was maintained with sevoflurane+0250\%+N20 50\% spontaneous respiration was maintained using Jackson Rees circuit. Surgery was started 15-17 minute after block was performed. A standardized intra operative fluid therapy was used in all patients $(6 \mathrm{ml} / \mathrm{kg} / \mathrm{h}$ of lactated ringer's solution). Continuous monitoring of Vitals was done HR, RR, SpO2 and NIBP were recorded before and after premedication, induction caudal block, after incision and every 5 minutes during the surgery.

\section{Caudal Technique}

After induction of anaesthesia, a caudal epidural block was performed in all patients in 2 groups. We put our patients in the left lateral decubitus position with knees drawn towards the chest with legs $90^{\circ}$ over the hips and $45^{\circ}$ over the knee (The lateral position is efficacious in paediatrics because it permits easy access to the airway when general anaesthesia administered prior to performing the caudal block)

A 23-gauge short-bevelled needle less than $4 \mathrm{~cm}$ in length was inserted 1-2 mm caudally halfway between both cornua, proximal to the vertex of the hiatus, at a $45^{\circ}$ angle in relation to the skin. After loss of resistance (Characteristic of passing the sacrococcygeal membrane), the needle was repositioned, decreasing angle to $20^{\circ}-30^{\circ}$ and inserted $2-3 \mathrm{~mm}$ into the vertebral canal under sterile conditions and study drug was injected. Aspiration tests should be repeated often during administration and should be slow, lasting about 90 seconds, to check for possible presence of Cerebrospinal fluid or blood. If the injection is too slow it may cause leakage of the drugs through the spinal roots; if is too rapid, it may cause a too high block or, in case of inadvertent intravascular injection, toxic plasmatic concentration proportional to infusion speed. Moreover, it was prudent to check if there is a subcutaneous Pompeii (Emphysema or bleb) resulting from incorrect placement of the needle.

During surgery, adequate analgesia was defined by hemodynamic stability, as indicated by the absence of an increase in heart rate or systolic blood pressure of more than $20 \%$ of the baseline values obtained just before surgical incision. Anaesthesia was discontinued when wound dressing was applied.

After recovery and when they were able to maintain a patent airway, the patients were transferred to the post anaesthesia care unit (PACU), where they remained for at least 2 hours before being transferred to the ward. Hemodynamic variables (MAP and HR) were recorded on administration to PACU and then every 30 minutes till patient was discharged to the ward.

Post-operative pain was assessed at the end of surgery by using Childers's Hospital of Eastern Ontario Pain Scale (CHEOPS, 0-10) and Faces Legs activity Cry Consolability Tool (FLACC, 0-10).

\section{We Monitored Following Data-}

1. Demographic data, intra-operative and post-operative variables.

2. Post-operative analgesia was assessed by using CHEOPS scale and FLACC tool.

3. The duration of analgesia was taken at the time of end of surgery until analgesia was required as evidenced by a pain score $>4$. 
4. The number of patients who received intravenous paracetamol as a rescue analgesic.

5. The total amount of paracetamol doses $(15 \mathrm{mg} / \mathrm{Kg}$ per dose) as a rescue analgesic needed after onset of pain.

6. The post-operative nausea vomiting (PONV) during first 24 hour after surgery was recoded, If needed, PONV was treated by ondansetron $0.1 \mathrm{mg} / \mathrm{Kg}$ intravenous.

7. Side effects from motor block, paraesthesia, and urine retention.

\section{Statistical Analysis}

All statistical analyses were performed using IBM SPSS statistics 20 . All the quantitative data were calculated by using student's t-test and for categorical data Chi-Square test was applied $\mathrm{P}<0.05$ was consider significant.

\section{RESULTS}

Sixty children were enrolled in this study and divide into two group 30 patients each. The patients' demographic data are presented in Table-1. The two groups were comparable in age, weight, ASA grade. The duration of incision and duration of surgery and duration of anaesthesia and Basal HR were comparable in Table-2. The caudal block was successful in all patients included in the study. All patients remained vitally stable throughout the procedure. The Duration of analgesia was shown longer in Group BD compared with Group B $(10.6+2.61)$ vs $(3.5+0.67) \quad \mathrm{P}<0.0001$. Group $\mathrm{BD}$ required significantly lower dose of injection Paracetamol than Group B in the first 24 hour after surgery $(\mathrm{P}<0.0001)$ in Table 3.

FLACC scores were comparable between the groups, CHEOPS scores at $30 \mathrm{~min}$. 1, 2 and 3 hours after surgery higher in Group B than in Group BD with statistical significance (Table 4). However, the differences in CHEOPS scores between the groups were $<1$ point. There were no significant differences in the incidence of adverse effect including. Vomiting one patient in Group B and fever two patient in Group B and one patient in Group BD. All adverse effects were also well controlled by a single dose of antiemetic. Dexamethasone associated adverse effects were not noted in the Group BD. (Table-5).

\begin{tabular}{|c|c|c|c|}
\hline Parameter & Group B & Group BD & p \\
\hline Age in Year & $2.15 \pm 1.19$ & $2.26 \pm 1.3$ & 0.737 \\
\hline Weight in kg. & $12.3 \pm 1.6$ & $12.6 \pm 1.4$ & 0.4427 \\
\hline ASA I:II & $24: 6$ & $25: 5$ & 0.4859 \\
\hline \multicolumn{3}{|c|}{ Table 1. Demographic Data } \\
\hline Value are Mean+SD or Age, Weight, ASA Grading P >0.05*
\end{tabular}

\begin{tabular}{|l|c|c|c|}
\hline & Group B & B.D. & p Value \\
\hline Time from caudal block to surgical incision (min) & $20+7$ & $18+6$ & 0.2396 \\
\hline Duration of Surgery (min) & $30 \pm 4.5$ & $29.8 \pm 4.0$ & 0.8563 \\
\hline Duration of Anaesthesia (min) & $40.1 \pm 5.7$ & $40.6 \pm 5.0$ & 0.7193 \\
\hline Baseline HR (min) & $116 \pm 9.2$ & $112 \pm 9.6$ & 0.1048 \\
\hline Table 2. Baseline Hemodynamic Parameters, Duration of Surgery, and \\
Anaesthesia \\
\hline Value are mean + SD.
\end{tabular}

\begin{tabular}{|c|c|c|c|}
\hline & $\begin{array}{c}\text { Group } \\
\text { B }\end{array}$ & $\begin{array}{c}\text { Group } \\
\text { BD }\end{array}$ & $\begin{array}{c}\text { p } \\
\text { Value }\end{array}$ \\
\hline Duration of Analgesia(Hours) & $3.5 \pm 0.67$ & $10.6 \pm 2.61$ & 0.0001 \\
\hline No. of times of analgesic dose needed in first 24 hours & $3.21 \pm 0.56$ & $1.1 \pm 0.43$ & 0.0001 \\
\hline Table 3. Duration of Analgesia and Analgesic Requirement \\
\hline
\end{tabular}

\begin{tabular}{|c|c|c|c|}
\hline CHEOPS & Group B & Group BD & p \\
\hline 30 min after surgery & $2.5(0.8)$ & $2.1(0.9)$ & 0.0740 \\
\hline 1 hr. & $2.7(1.0)$ & $2.0(1.0)$ & 0.0088 \\
\hline 2 hr. & $2.1(1.1)$ & $1.5(1.0)$ & 0.0284 \\
\hline 3 hr. & $1.7(1.0)$ & $1.2(1.0)$ & 0.0577 \\
\hline FLACC & Group B & Group BD & P value \\
\hline 30 min after surgery & $1(1.2)$ & $0.6(1.5)$ & 0.2588 \\
\hline 1 hr. & $1.3(1.1)$ & $0.7(1.4)$ & 0.0700 \\
\hline 2 hr. & $0.9(1.5)$ & $0.3(0.8)$ & 0.0581 \\
\hline $3 \mathrm{hr}$. & $0.4(0.9)$ & $0.1(0.4)$ & 0.1006 \\
\hline
\end{tabular}

Table 4. Postoperative CHEOPS and FLACC Scores Data are Shown as Mean + SD CHEOPS: Children's Hospital of Eastern Ontaria Pain Scale, FLACC: Faces Legs Activity Cry Consolability Tool

\begin{tabular}{|c|c|c|}
\hline & Group B & Group D \\
\hline Vomiting & 1 & 0 \\
\hline Fever & 2 & 1 \\
\hline Wound infection & 0 & 0 \\
\hline \multicolumn{3}{|c|}{ Table 5. Complications } \\
\hline
\end{tabular}

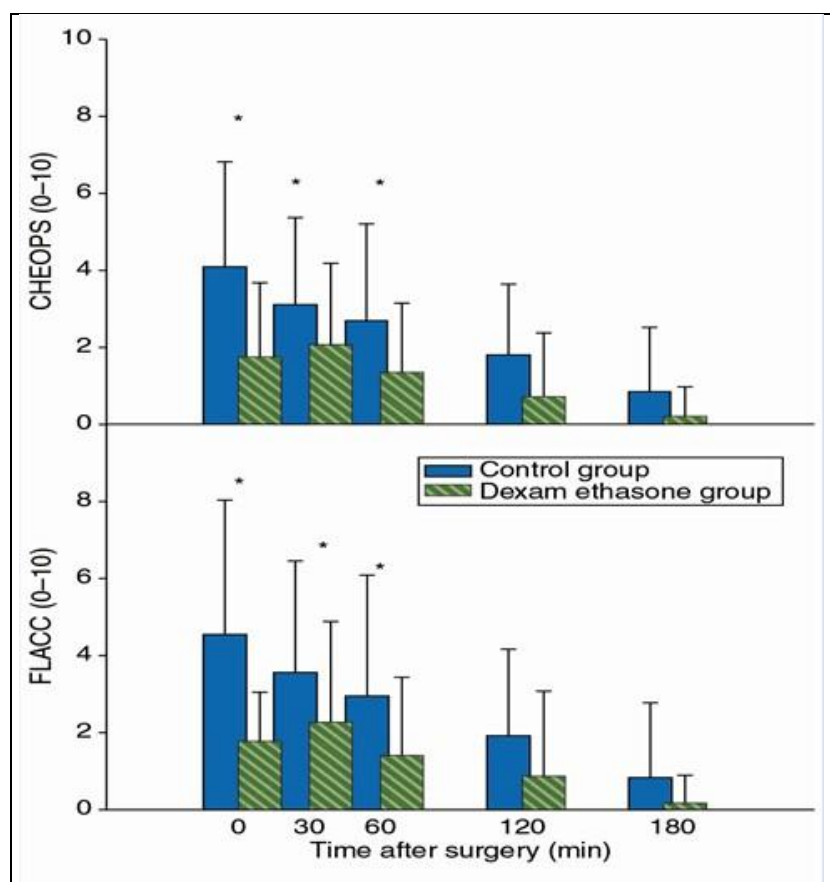

Figure 1. Postoperative Pain Scores. Pain Scores Using CHEOPS and FLACC Assessed at the PACU were Significantly Lower 1 hr. after Surgery in the Dexamethasone Group than in the Control Group

\section{DISCUSSION}

Dexamethasone is a highly selective, long acting very potent corticosteroid. Dexamethasone might have a local anaesthetic effect on nerve by direct membrane action.(13) So it prolongs the duration of analgesia. Another mechanism involves the effect of dexamethasone on the spinal cord. The transcription factor nuclear factor- $\mathrm{k} \beta$ (NF-k $\beta$ ) is expressed throughout the nervous system and play important role in the development of pathological pain.(14) Dexamethasone could regulate NF-k $\beta,{ }^{(15)}$ more specifically, epidural injection inhibit development of, hyperalgesia with reduction in NF-k $\beta$ level.(16)

Therefore, children of Group BD were without pain postoperative period for longer time then the Group B due to prevention of hyperalgesia at the spinal cord level. No significant side effects have been reported for epidural

dexamethasone.(17) Although there is no first evidence regarding the safety of administered in caudal route in children. The safety of methylparaben and propylparaben the preservative included in dexamethasone injection has been 
proven even in intrathecal injection of human and animal model.(18-19) One of the benefits of dexamethasone has been decrease in post-operative nausea vomiting. Dexamethasone may extent and antiemetic action via prostaglandin antagonism, serotonin inhibition in the gut and release of endorphins. Thus, validity of CHEOPS for assessment of pain valid only during immediate post-operative period. Caudal block used as regional anaesthesia in paediatric patients for lower abdominal surgeries. It is easy and low failure rate. Short duration of surgeries can be performed solely under caudal block.

We evaluated the effect of dexamethasone in caudal block for inguinal hernia repair in children in terms of prolongation of duration of analgesia, requirement of rescue analgesia and any side effects. The present study showed that the addition of

$0.1 \mathrm{mg} / \mathrm{Kg}$ dexamethasone to $0.25 \%$ bupivacaine 1 $\mathrm{ml} / \mathrm{Kg} \cdot(20,21,22)$

\section{We found that Dexamethasone-}

- Prolonged the duration of analgesia.

- Reduce the rescue analgesic.

- Decrease incidence of PONV.

Not associated with increased sedation or prolonged motor block. S. Choudhary et al in these studies found that dexamethasone with ropivacaine prolonged the effect of analgesic. Kimem also found the same effect in children undergoing orchiopexy. Yousuf GT et al compared and their result show it enhances the duration of analgesia and subsequently decrease requirement of post-operative analgesia. The risk to patient of a single dose of dexamethasone appear to be minimal. We found no report in the literatures of complication from the use of single dose of epidural dexamethasone in paediatric surgery. (The cost of dexamethasone is relatively low which make routine use is reasonable).

\section{Limitations}

- We did not evaluate some adverse effect.

- Increase the blood glucose level adrenal suppression.

- We did not want to invasive techniques for further bloodsampling.

- In previous studies they prove small does not associated with significant side effect.(23)

\section{CONCLUSIONS}

The addition of $0.1 \mathrm{mg} / \mathrm{Kg}$ of dexamethasone either caudally or through the intravenous route to caudal $0.25 \%$ bupivacaine significantly prolongs the duration of post-operative analgesia and improves antiemetic control without an increase in the incidence of side effects, especially blood glucose.

\section{ACKNOWLEDGEMENT}

The authors acknowledge Dr. Sudhir B Chandna (Head of the Department of Paediatric surgery) for his constant guidance,
Dr. Shruti M. Shah, M.D. Professor and Head of Department of Anaesthesiology, N.H.L. Municipal Medical College, Sheth V.S. General Hospital, Dr. Pankaj R. Patel (Dean P.G. Director, N.H.L. Municipal Medical College, Sheth V. S. General Hospital Ahmedabad) and Dr. S.T. Malhan (Superintendent, V. S. General Hospital) for allowing me to conduct this study in their institution. The authors thank all patients who participated in this study.

\section{REFERENCES}

[1] Stewart DW, Ragg PG, Sheppard S, et al. The severity and duration of post-operative pain and analgesia requirement in children after tgonsilectomy, orchidopexy or inguinal hernia repair. Paediatr Aneaths 2012;22(2):136-43.

[2] Ho D, Keneally JP. Analgesia following paediatric daysurgical orch-idopexy and herniotomy. Paediatr Anaesth 2000;10(6):627-31.

[3] Young KD. Paediatric procedural pain. Ann Emerg Med 2005;45(2):160-71.

[4] Henneberg WS, Nilsson BL. Acute paediatric pain, review. Current Anaesthesia \& Critical Care 2007;18:126-34.

[5] Silvani P, Camporesi A, Agostino MR, et al. Caudal Anaesthesia in paediatrics: an update. Minerva Anestesiol 2006;72(6):453-9.

[6] De Beer Da. Thomas ML. Caudal additives in children solutions or problems? Br J Anesth 2003;90(4):487-98.

[7] Engelman E, Marsala C. Bayesian enhanced meta-analysis of post-operative analgesic efficacy of additives for caudal analgesia in children. Aeto Anaesthesia Scand 2012;56(7):817-32.

[8] Ansermino M, Basa R, Varidebeek C, et al. Nonopioid additive to local anaesthetic for caudal block in children. a systematic review. Paediatric Anath 2003;13(7)561-73.

[9] Singh R, Kumar N, Sing P. Randamozed controlled trial complaining morphine or clonidine with bupivacaine for caudal analgesia in children undergoing upper abdomen surgery. Br J Anesth 2011;106(1):96-100.

[10] De Oliveira GS Jr. Almedia MD, Benzon HT, et al. Perioperative single dose systemic dexamethasone for postoperative pain: a meta-analysis of randomized controlled trial. Anaesthesiology 2011;115(3):575-88.

[11] Voepel-Lewis T, Zanotti J, Dammeyer JA, et al. Reliability and validity the face, leg activity, cry consolability behavioral tool in assessing acute pain in critically ill patients. Am J Crit Care 2010;19(1):55-61.

[12] Crellin D, Sallivan TP, Babl FE, et al. Analysis of the validation of existing behavioural pain and distress scale for use in the procedural setting. Paediatric Anaesth 2007;17(8):720-33.

[13] Johansson A, Hao J, Sjolund B. Local corticosteroid application blocks transmission in normal nociceptive Cfibres. Acta Anaesthesial Scand 1990;34(5):335-8.

[14] Niederberger E, Geisslinger G. The IKK-NF-kappaB pathway: a source for novel molecular drug targets in pain therapy? FASEB J 2008;22(10):3432-42. 
[15] De Bosscher K, Berghe VW, Haegeman G. The interplay between the glucocorticoid receptor and nuclear factorkappaB or activator protein-1: molecular mechanism for gene repression. Endocr Rev 2003;24(4):488-522.

[16] Xie W, Liu X, Xuan H, et al. Effect of betamethasone on neuropahic pain and cerebral expression of NF-kappaB and cytokines. Neurosci Lett 2006;393(2-3):255-9.

[17] Ahadian FM, McGreevy K, Schulteis G. Lumbar transforaminal epidural dexamethasone: a prospective, randomized, double-blind, doe response trial. Reg Anesth Pain Med 2011;36(6):572-8.

[18] Eisenach JC, Hood DD, Curr R. Phase 1 human safety assessment of intrathecal neostigmine containing methyland propylparabens. Anesth Analg 1997;85(4):842-6.

[19] Gurun MS, Leinbach R, Moore L, et al. Studies on Safety of glucose and parabene-containing neostigine for intrathecal administration. Anesth Analg 1997;85(2):317-23.
[20] Kim EM, Lee JR, Koo BN, et al. Analgesic efficacy of caudal dexamethasone combined with ropivacaine in children undergoing orchiopexy. Br J Anaesth 2014;112(5):88591.

[21] Choudhary S, Dogra J, Dogra J, et al. Evaluation of caudal dexamethasone with ropivacaine for postoperative analgesia in paediatric herniotomies: a randomised controlled study. Indian J Anaesth 2016;60(1):30-3.

[22] Abd-Elshafy SK, Yacoup AM, Abdulla EE, et al. A new look on adding dexamethasone as an adjuvant to caudal bupivacaine; efficacy on postoperative pain and vomiting in paediatric patients. Pain Physician 2016;19(6):E841E52.

[23] Yousef GT, Ibrahim TH, Khder A, et al. Enhancement of ropivacaine caudal analgesia using dexamethasone or magnesium in children undergoing inguinal hernia repair. Anaesthesia Essays and Researches 2014;8(1):13-19. 